\title{
Internet-based Administration of Instruments, Usage and Accounting in Shared Facilities
}

\author{
Shu-You Li and Vinayak P. Dravid*
}

NUANCE Center, *Materials Science \& Engineering, Northwestern University, Evanston, IL 60208

Resource sharing has become a necessity for modern scientific research because of the increasing expense and complexity of instruments [1]. Many universities and large companies have set up centralized facilities to serve researchers from different departments. Principal Investigators also collaborate in investigation and maintenance of shared instruments.

There are some major concerns that come up with resource sharing, including:

- How to control access to the facility?

- How to use schedule the instruments efficiently?

- How to keep usage and maintenance records of the instruments?

- How to share or backup the experimental data while keeping research secrets?

- How to inform technical staff gets when an instrument needs attention?

- How to maintain an up-to-date user database?

- How to get performance reports of the instruments' usage?

- How to manage allocation of costs associated with the instruments or invoice?

In today's digital age, managers want all these needs to be met with carefully designed, secure software. As the largest shared facility at Northwestern University, serving more than 500 users, we have implemented a software reservation and billing program that we developed and launched in 2003 (Facility Online Manager, FOM ${ }^{\mathrm{TM}}$ ) [2]. With three years' experience, we have upgraded the software to a fully enhanced package for internet-based administration of instruments in shared facilities. Features now include:

1. Local wireless network for access control switches and data servers

2. Magnetic card readers for instruments access control

3. Accounting and inventory records

4. Password protected remote access to user's experimental data

5. Performance reports of instrument usage

6. Automated backup of management and user data.

A sketch map of FOM implementation is shown in fig. 1 next page. We installed magnetic card readers in every room. Users may reserve sessions with any internet-connected computer, just like common scheduling softwares do. However unlike other scheduling softwares, we allow logon and use of the instruments with only authorized magnetic cards. This ultimately eliminated unauthorized access to the instruments.

Figure 2 shows a typical user interface. You can see links to authorized instruments for the current user and other functions at left side of the window. The operation is fairly straightforward - users simply click on available time slots to reserve a session, and swipe the magnetic card just before use the instrument. A free demo of the software is available at http://www.nuance.northwestern.edu/. 


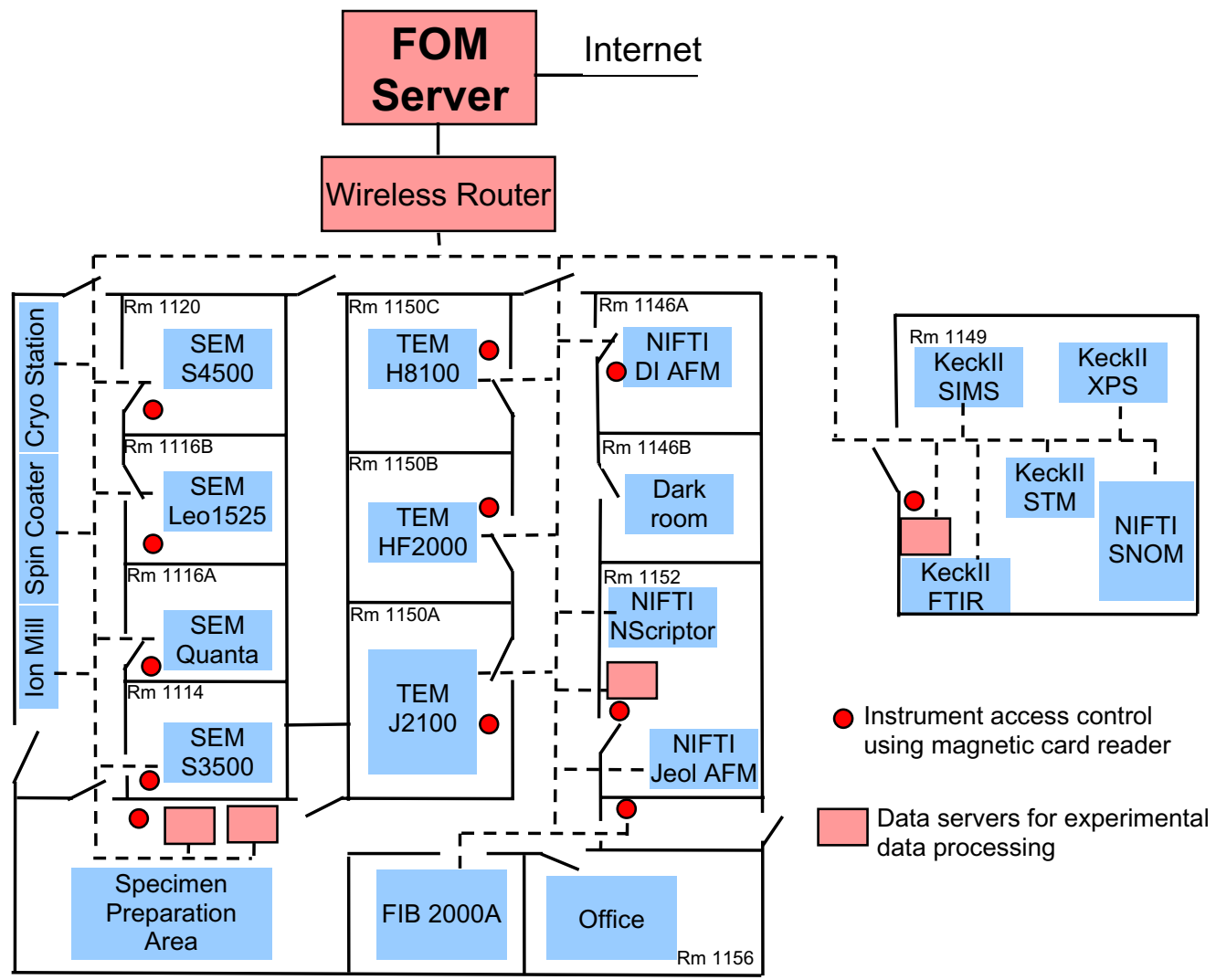

Fig. 1. NUANCE floor plan and distribution of FOM controllers.

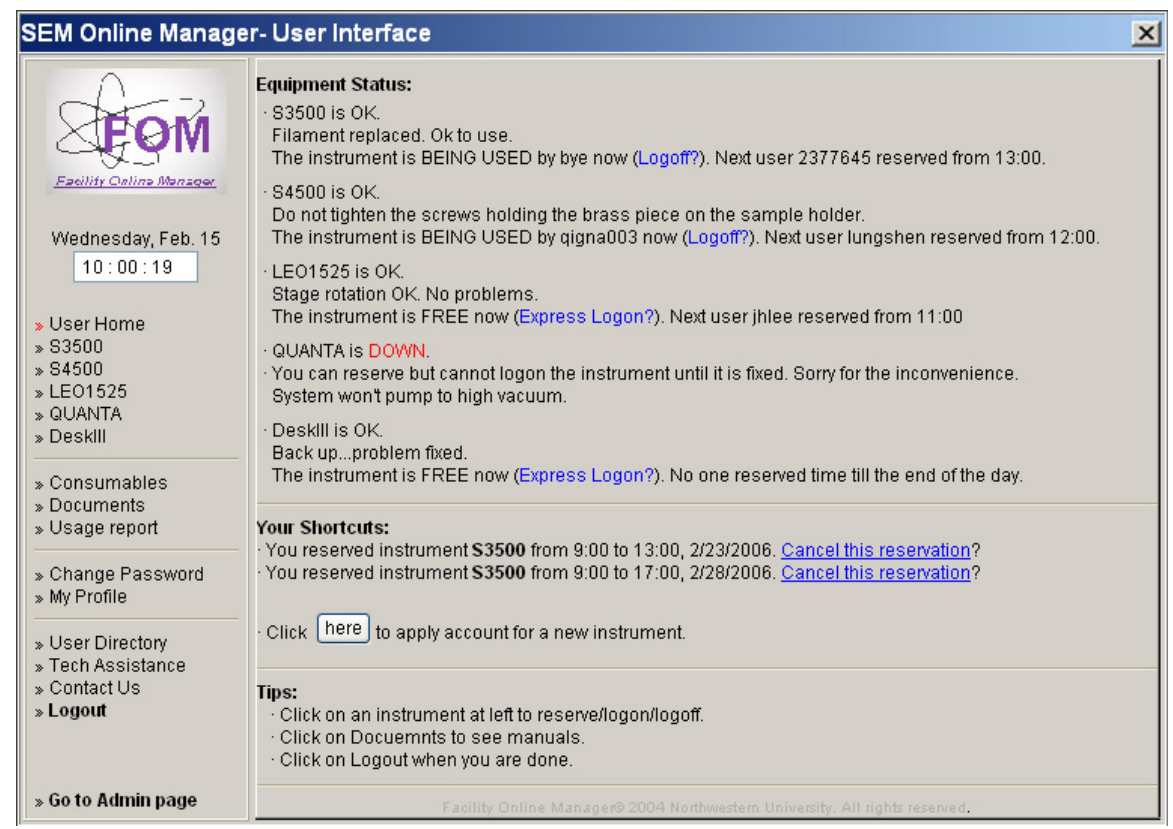

Fig. 2. A screenshot of FOM showing links to available instruments and other features.

\section{References}

[1] Midsize Facilities: Infrastructure for Materials Research, The National Academies Press, 2005.

[2] S.Y. Li and V.P. Dravid, FOM -- An Online Reservation and Fiscal Management System for Shared Facilities, Microscopy and Microanalysis 2003, San Antonio, Texas. Aug. 3-7, 2003. 